\title{
Evaluation of Pulmonary Function After Radiotherapy Using Helical Tomotherapy for Breast Cancer Treatment: Prospective Study
}

\author{
Fatma TEKE, ${ }^{1}$ Melike DEMIR, ${ }^{2}$ Pakize Gamze ERTEN BUCAKTEPE,, ${ }^{3}$ Mehmet Ali KAYA, ${ }^{1}$ \\ Mehmet Hakan DOĞAN, ${ }^{1}$ Mehmet KÜÇÜKÖNER, ${ }^{4}$ Seyit Burhanedtin ZiNCiRCiOĞLU,' ${ }^{1}$ Memik TEKE ${ }^{5}$
}

\begin{abstract}
'Department of Radiation Oncology, Dicle University Faculty of Medicine, Diyarbakır-Turkey
${ }^{2}$ Department of Pulmonary Diseases, Dicle University Faculty of Medicine, Diyarbakır-Turkey

${ }^{3}$ Department of Family Medicine, Dicle University Faculty of Medicine, Diyarbakır-Turkey

${ }^{4}$ Department of Medical Oncology, Dicle University Faculty of Medicine, Diyarbakır-Turkey

${ }^{5}$ Department of Radiology, Dicle University Faculty of Medicine, Diyarbakır-Turkey
\end{abstract}

\begin{abstract}
OBJECTIVE
Purpose of the present study was to investigate acute pulmonary changes using pulmonary function tests (PFTs) after breast cancer irradiation with helical tomotherapy (HT).

\section{METHODS}

Forty patients were included in this study. Pretreatment and 3 months after completion of radiotherapy (RT), values of forced vital capacity (FVC), forced expiratory volume in first second (FEV1), and FEV1/ FVC ratio were measured and recorded.

\section{RESULTS}

Restrictive pattern was seen in 4 patients in baseline PFTs and moderate deterioration was observed in their measurements of PFT at 3 months after RT. Obstructive pattern was defined in only 1 patient in baseline PFTs and it remained unchanged after RT. Mild obstructive pattern in 4 patients and mild restrictive pattern in 3 patients had developed at 3 months after RT.
\end{abstract}

\section{CONCLUSION}

Minimal changes that result in mild restrictive and obstructive pattern in PFTs can be seen in acute phase after RT with HT.

Keywords: Breast cancer; radiation pneumonitis; tomotherapy.

Copyright $\odot$ 2016, Turkish Society for Radiation Oncology

\section{Introduction}

Radiation-induced lung disease (RILD) is one of the most common clinical toxicities resulting from thoracic radiotherapy. The cells in the alveolar space are damaged by radiation and early damage progresses to an acute exudative inflammation process. In this way, radiation pneumonitis (RP) is manifested within 4-12 weeks after completion of radiotherapy.[1] Subclinical acute lung injury is experienced by most of these patients. Pulmonary function test (PFT) is a useful tool to assess the respiratory impairment and pulmonary function is com- 
monly measured by evaluating the FVC, FEV1, FEV1/ FVC.[2] The main factors responsible for pulmonary toxicity are irradiated lung volume and radiation dose. Although the strong correlations between the different dosimetric parameters, there is no sharp threshold dose (Vdose) associated with RP risk due to different radiation techniques and applications.[3] Conventional 3D conformal radiotherapy (3DCRT) that use parallel-opposed tangential beams is most common technique in breast cancer irradiation and it's complications are well documented. In breast cancer irradiation, the increased use of recent more sophisticated radiotherapy techniques such as intensity-modulated radiation therapy (IMRT) and helical tomotherapy (HT) allows complex treatment plan according to patient's anatomy. Particularly HT use all gantry angles because of rotational delivery and it could cause low doses to a greater volume of healthy tissues, especially the contralateral breast and lung. The current question is how these techniques will impact clinical outcomes. These techniques have been evaluated and demonstrated dosimetric advantages in many studies.[4-6] However, to our knowledge, presence of acute lung injury in breast cancer irradiation using HT has been investigated prospectively in very few studies,[7] although many studies[8-14] including different RT techniques have shown changes in pulmonary functions after breast and mostly lung cancer irradiation. The purpose of this prospective study was to investigate acute pulmonary changes that could be caused radiotherapy using pulmonary function tests (PFTs) in breast cancer patients treated with HT.

\section{Materials and Methods}

\section{Patients}

Between April 2015 and September 2015, proven histopathologic features of breast cancer, age 18-75 years and stage I-III, female patients who were performed breast conserving surgery or mastectomy and required adjuvant radiotherapy were intended to include in this prospective study after obtaining informed consent. The exclusion criteria were a history of chronic respiratory disease, previous RT to thorax, concomitant malignancy, the presence of respiratory symptoms for more 2 weeks within previous one year. Ultimately, 56 patients met the selection criteria for this study that was approved by local research ethic board. Forty patients completed both PFTs at two time points. All patients underwent complete blood count, chest radiograph and PFTs pre-RT and 3 months after completion of RT to evaluate baseline status and acute pulmonary changes.

\section{Radiotherapy}

All patients were positioned using a breast board (CIV$\mathrm{CO}$ ) with their head turned to the contralateral side and the ipsilateral arm raised above their head in a supine position and computed tomography (CT) images with $3.0 \mathrm{~mm}$ thickness were obtained for RT planning. For whole breast or chest wall RT with or without lymph nodes, the planning target volume (PTV) and critical structures including the ipsilateral and contralateral lung, heart, esophagus, spinal cord, contralateral breast and skin were defined and contoured according to the recommendations of the breast cancer atlas for radiation therapy planning consensus definitions of RTOG (the Radiation Therapy Oncology Group) (available at: http://www.rtog.org/CoreLab/ContouringAtlases/ BreastCancerAtlas.aspx). The lumpectomy bed was also contoured as a boost PTV with $1 \mathrm{~cm}$ expansion in the patients were performed breast-conserving surgery and 10 or 16 Gy was prescribed as boost dose for 13 lumpectomy cavity and 4 incision scar. In the case of lymph node positivity, lymphatic PTV was created. Loco-regional RT volume was defined as the axillary and supraclavicular lymph nodes with or without ipsilateral internal mammary nodes additional to the chest wall or breast. Local RT was defined as target volume of the chest wall or breast. The volume contours and CT images were transferred to the Tomotherapy $\mathrm{H}$ system (Accuray Inc., Sunnyvale, CA) to create treatment plans. $\mathrm{TH}$ plans were created with a field width of $5.048 \mathrm{~cm}$, fixed jaw mode and a pitch of 0.287 . The median modulation factor was 3.0 and it ranged from 2.0 to 3.5. Dose prescription was $50 \mathrm{~Gy}$ in 25 fractions of $2.0 \mathrm{~Gy}$ daily.

\section{Evaluation of Radiation Doses}

As dose constraints for the PTV, 1) D95 was defined as the minimum dose delivered to $95 \%$ of the PTV and D95 $\geq 95 \%$ of the prescribed dose were satisfied. 2) V95\% (V47.5 Gy) was defined as the percentage of the PTV receiving at least $95 \%$ of the prescribed dose and V95\% $\geq 95 \%$ were satisfied. For PTV, the parameter V107 (V53.5 Gy) was defined as the percentage of the PTV receiving at least $107 \%$ of the prescribed dose and was used to assess the maximum doses. Dosevolume histograms (DVHs) for the PTV, lung and the heart were calculated for each patient. Ipsilateral and total mean lung dose (MLD), ipsilateral lung volume receiving 5 and 20 Gy (V5 and V20), values of mean dose, V5, and V30 of the heart derived from DVHs were evaluated.

The Conformity Index (CI) was calculated as the ratio of the V95\% over the volume of breast or chest 


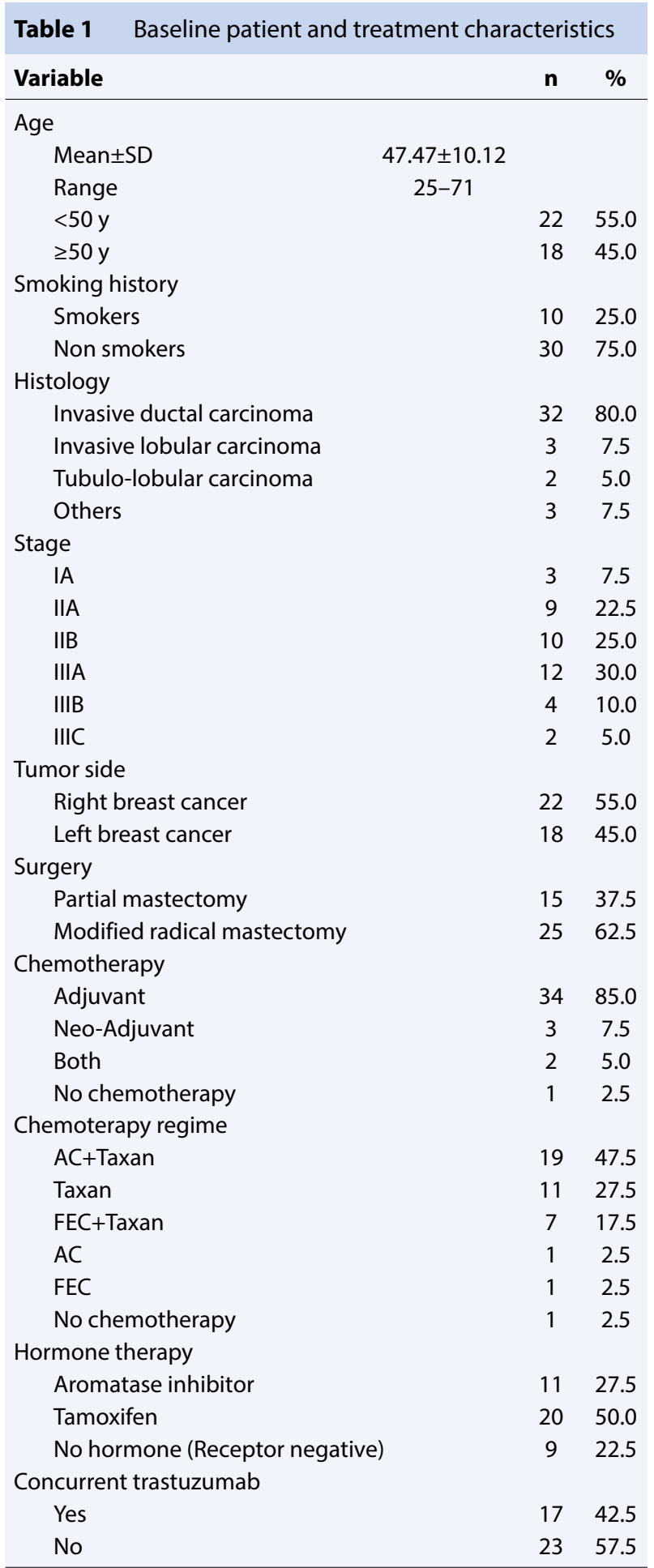

AC: Adriamycin, cyclophosphamide; FEC: 5-Fluorouracil, epirubicin, cyclophosphamide.

wall PTV. The Homogeneity Index (HI) was calculated by the following formula.

$\mathrm{HI}=(\mathrm{D} 2 \%-\mathrm{D} 98 \%) / \mathrm{D} 50 \%$

\section{Chemotherapy and Hormone therapy}

Thirty nine patients had been given neoadjuvant and/ or adjuvant chemotherapy including anthracycline and/or taxan-containing regimens. The patients had hormone receptor positivity were given aromatase inhibitor or tamoxifen with or without luteinizing hormone-releasing hormone (LHRH) analogue after completion of RT. One patient with partial mastectomy received tamoxifen plus LHRH analogue but not chemotherapy because she had stage IA disease. The patients whose were Her2 (3+) and Silver Enhanced In Situ Hybridization (+) (SISH + ) in the case of Her2 (2+) received concomitant Trastuzumab with RT and were continued 1 year after completion of RT.

\section{Pulmonary Function Tests}

Evaluation of pulmonary function was based on spirometric measurement (ZAN 300: ZAN Messgerate $\mathrm{GmbH}$, Oberthulba, Germany). Pre-treatment and 3 months after completion of RT, values of forced vital capacity (FVC), forced expiratory volume in first second (FEV1) and FEV1/FVC ratio were monitored and recorded as percentages of predicted values. All tests were assessed the recommendations of the American Thoracic Society (ATS)/European Respiratory Society (ERS).[15]

\section{Statistical analysis}

Data were analyzed using SPSS version 16.0 statistical software (SPSS, Chicago, IL, USA). All data were expressed as median and/or mean \pm standard deviation. Patients' demographic, clinical and dosimetric data were analyzed using Kolmogorov-Smirnov to test whether for normal distribution. Since variables were non-normally distributed and/or were ordinal, correlation coefficients and their significance were calculated using Spearman test to examine the strength of the relationship between variables at two time points. The Wilcoxon test was used to test the significance of dependent variables between pre-treatment and 3 months after RT. Mann-Whitney U test was used to identify the relation between independent groups such as age ( $<50$ and $\geq 50$ years), RT volume (local RT and loco-regional RT), ipsilateral lung volume receiving dose $\geq 20$ Gy (V20, $\geq 20 \%$ and $<20 \%, \geq 25$ and $<25, \geq 30$ and 30), use of tamoxifen (yes and no) and also use of concomitant Trastuzumab (yes and no).

\section{Results}

Baseline patient and treatment characteristics were summarized in Table 1. Dosimetric parameters of 


\begin{tabular}{|c|c|c|c|}
\hline Parameter & Mean \pm SD & Median & Range \\
\hline Treatment time (min) & $6.82 \pm 3.03$ & 6.10 & $3.8-17.9$ \\
\hline \multicolumn{4}{|l|}{ PTV } \\
\hline Dmean & $52.19 \pm 1.48$ & 51.67 & $50.30-56.37$ \\
\hline Dmin & $35.95 \pm 4.79$ & 36.58 & $18.14-42.49$ \\
\hline Dmax & $59.10 \pm 4.44$ & 56.86 & $54.37-70-18$ \\
\hline V95 & $97.44 \pm 2.14$ & 97.45 & $87.63-100.00$ \\
\hline V107 & $26.34 \pm 25.11$ & 19.17 & $0.42-75.96$ \\
\hline $\mathrm{Cl}$ & $0.97 \pm 0.25$ & 0.97 & $0.88-1.05$ \\
\hline $\mathrm{HI}$ & $0.20 \pm 0.09$ & 0.18 & $0.07-0.38$ \\
\hline \multicolumn{4}{|l|}{ Ipsilateral lung } \\
\hline Dmean & $14.94 \pm 2.57$ & 15.22 & $6.93-20.52$ \\
\hline V5 & $83.16 \pm 16.64$ & 84.94 & $22.45-100.00$ \\
\hline V20 & $24.30 \pm 5.55$ & 25.35 & $10.41-34.68$ \\
\hline \multicolumn{4}{|l|}{ Contralateral lung } \\
\hline Dmean & $7.00 \pm 2.25$ & 7.09 & $1.24-11.25$ \\
\hline V5 & $56.53 \pm 22.44$ & 56.03 & $0.00-100.00$ \\
\hline V20 & $2.23 \pm 3.15$ & 1.12 & $0.00-13.23$ \\
\hline \multicolumn{4}{|l|}{ Total lung } \\
\hline Dmean & $11.29 \pm 2.07$ & 11.54 & $4.36-16.22$ \\
\hline \multicolumn{4}{|l|}{ Heart } \\
\hline Dmean & $9.32 \pm 2.14$ & 9.25 & $0.50-13.42$ \\
\hline V5 & $77.87 \pm 24.70$ & 83.71 & $0.00-100.00$ \\
\hline V25 & $2.94 \pm 2.74$ & 2.61 & $0.00-9.74$ \\
\hline V30 & $1.52 \pm 1.75$ & 0.65 & $0.00-6.50$ \\
\hline \multicolumn{4}{|l|}{ Contralateral breast } \\
\hline Dmean & $6.30 \pm 1.84$ & 6.51 & $0.46-9.81$ \\
\hline
\end{tabular}

PTV and organs at risk were presented in Table 2. The target dose homogeneity and conformity index were perfect in this study. PFTs measurements preRT and 3 months after RT and comparison of parameters between two time points were presented in Table 3. Means of percent of decrease in FEV1 and FVC was found as $0.06 \pm 0.07$ and $0.06 \pm 0.06$, respectively. There were statistically significant changes in PFTs at 3 months after RT $(\mathrm{p}<0.05)$. We compared the means of percent decrease in FEV 1 and FVC from before RT to 3 months after RT in subgroups (Table 4). In the patients were given concurrent Trastuzumab with RT and the group had the value of ipsilateral lung V20 was $\geq 30$, mean of percent decrease in FVC at 3 months after RT was significantly higher $(p=0.022$ and $p=0.019$, respectively). However, age, RT volume and use of tamoxifen had no effect on means of percent decrease in FEV 1 and FVC from before RT to 3 months after RT. In correlation analysis, there was no statistically significant correla- tion between irradiated lung volumes including values of total lung Dmean, ipsilateral lung Dmean, V5 and V20 and measurements of PFT at 3 months after RT ( $>>0.05)$. However, there was negative correlation between age and FEV1/FVC at 3 months after $\mathrm{RT}(\mathrm{r}=-0.321$ and $\mathrm{p}=0.043)$. The patients were diagnosed with neither clinical nor radiological pulmonary complications after RT during the study period. According to baseline measurements of PFT, restrictive pattern was seen in 4 patients and a moderate deterioration was observed in their measurements of PFT at 3 months after RT. In the evaluation at 3 months after RT, mild restrictive pattern newly developed in 3 patients additional to 4 patients at baseline. The obstructive pattern was defined in only one patient in baseline PFTs and it remained unchanged after RT. Additional to this patient, mild obstructive pattern was developed in 4 patients at 3 months after RT. Table 5 shows characteristics of these restrictive and obstructive patients. 
Table 3 Parameters of pulmonary function tests and hemogram at two time points and results of Wilcoxon Test

\begin{tabular}{|c|c|c|c|c|c|}
\hline \multirow[t]{2}{*}{ PFT } & \multicolumn{2}{|c|}{ Pre-RT (T0) } & \multicolumn{2}{|c|}{$\begin{array}{c}\text { At } 3 \text { mo after } \\
\text { RT (T1) }\end{array}$} & \multirow{2}{*}{$\begin{array}{c}\text { Comparison of } \\
\text { T0 and T1 } \\
\text { p }\end{array}$} \\
\hline & Median & Range & Median & Range & \\
\hline FVC (\%) & 93.00 & $58-117$ & 88.00 & $49-120$ & 0.000 \\
\hline FEV1 (\%) & 89.00 & $52-122$ & 82.50 & $49-120$ & 0.000 \\
\hline FEV1/FVC (\%) & 84.0 & $65-108$ & 84.00 & 64-106 & 0.073 \\
\hline Hemoglobin & 11.87 & $7.32-13.40$ & 12.58 & $10.06-14.28$ & 0.000 \\
\hline WBC & 6.90 & $2.93-40.95$ & 6.01 & $3.10-9.93$ & 0.002 \\
\hline Platelet & 288.35 & $164.00-478.20$ & 231.15 & $140.90-307.70$ & 0.000 \\
\hline
\end{tabular}

PFT: Pulmonary function test; FVC: Values of forced vital capacity; FEV1: Forced expiratory volume in first second; WBC: White Blood Cell; RT: Radiotherapy.

\begin{tabular}{|c|c|c|c|}
\hline $\begin{array}{l}\text { Comparison of } \mathrm{m} \\
\text { months after RT }\end{array}$ & ann & $\begin{array}{l}\text { in FEV } 1 \text { and FVC } \mathrm{f} \\
\text { Test in subgroups }\end{array}$ & e RT to 3 \\
\hline Group & $\mathbf{n}$ & $\begin{array}{c}\text { Change in FEV1 } \\
\text { p }\end{array}$ & $\begin{array}{c}\text { Change in FVC } \\
p\end{array}$ \\
\hline Age & & 0.22 & 0.24 \\
\hline$<50 y$ & 22 & & \\
\hline$\geq 50 y$ & 18 & & \\
\hline Concurrent trastuzumab & & 0.05 & 0.02 \\
\hline YES & 17 & & \\
\hline NO & 23 & & \\
\hline Tamoxifen & & 0.66 & 0.25 \\
\hline YES & 20 & & \\
\hline NO & 20 & & \\
\hline RT volume & & 0.07 & 0.25 \\
\hline Local RT & 8 & & \\
\hline Loco-regional RT & 32 & & \\
\hline Ipsilateral lung V20 (Group 1) & & 0.25 & 0.73 \\
\hline$<20$ & 7 & & \\
\hline$\geq 20$ & 33 & & \\
\hline Ipsilateral lung V20 (Group 2) & & 0.74 & 0.73 \\
\hline$<25$ & 19 & & \\
\hline$\geq 25$ & 21 & & \\
\hline Ipsilateral lung V20 (Group 3) & & 0.61 & 0.01 \\
\hline$<30$ & 36 & & \\
\hline$\geq 30$ & 4 & & \\
\hline
\end{tabular}

FVC: Values of forced vital capacity; FEV1: Forced expiratory volume in first second.

\section{Discussion}

One of the primary concerns for breast cancer RT is the issue of pulmonary toxicity. Data related pulmonary toxicity has been obtained mostly from studies on lung cancer irradiation because lung exposure is lower in breast irradiation than that in lung cancer. Although it was found strong correlation between RILD and Vdose in lung cancer irradiation, this relationship is smaller in local or loco-regional breast cancer RT.[16] To our knowledge, this is the first study investigating prospectively the acute pulmonary toxicity linked to breast radiotherapy in covantional doses with helical tomotherapy although there are a lot of study[7-9,16-18] including different RT techniques. Van Parijs et al.[7] evaluated pulmonary function of 
Table 5 The characteristics of restrictive and obstructive patients

\begin{tabular}{|c|c|c|c|c|c|c|c|c|c|c|c|c|}
\hline \multirow[t]{3}{*}{ Patient } & \multirow[t]{3}{*}{ Age } & \multirow{3}{*}{$\begin{array}{c}\text { RT } \\
\text { field }\end{array}$} & \multirow{3}{*}{$\begin{array}{l}\text { Total } \\
\text { MLD }\end{array}$} & \multirow{3}{*}{$\begin{array}{l}\text { Ipsilateral } \\
\text { lung MLD }\end{array}$} & \multirow{3}{*}{$\begin{array}{l}\text { Ipsilateral } \\
\text { lung V5 }\end{array}$} & \multirow{3}{*}{$\begin{array}{l}\text { Ipsilateral } \\
\text { lung V20 }\end{array}$} & \multicolumn{6}{|c|}{ PFT } \\
\hline & & & & & & & \multicolumn{3}{|c|}{ BeforeRT } & \multicolumn{3}{|c|}{ At 3 mo. After RT } \\
\hline & & & & & & & $\begin{array}{l}\text { FEV1 } \\
\text { (\%) }\end{array}$ & $\begin{array}{l}\text { FVC } \\
\text { (\%) }\end{array}$ & $\begin{array}{l}\text { FEV1 } \\
\text { /FVC }\end{array}$ & $\begin{array}{l}\text { FEV1 } \\
\text { (\%) }\end{array}$ & $\begin{array}{l}\text { FVC } \\
\text { (\%) }\end{array}$ & $\begin{array}{l}\text { FEV1 } \\
\text { /FVC }\end{array}$ \\
\hline $\mathrm{R} 1^{* *}$ & 58 & LR & 8.45 & 11.25 & 70.31 & 10.41 & 84 & 88 & 82 & 73 & 78 & 78 \\
\hline $\mathrm{R}^{* *}$ & 71 & LR & 12.22 & 15.22 & 92.30 & 27.78 & 92 & 88 & 84 & 79 & 76 & 82 \\
\hline $\mathrm{R}^{* *}$ & 33 & L & 10.47 & 14.92 & 76.70 & 22.68 & 87 & 85 & 89 & 77 & 69 & 98 \\
\hline $\mathrm{R} 4^{*}$ & 60 & LR & 9.54 & 12.08 & 73.80 & 19.50 & 89 & 79 & 93 & 71 & 69 & 84 \\
\hline $\mathrm{R}^{*}$ & 44 & LR & 12.88 & 15.87 & 99.0 & 25.34 & 57 & 72 & 67 & 52 & 67 & 66 \\
\hline $\mathrm{R}^{*}$ & 33 & LR & 14.21 & 20.52 & 100.0 & 33.26 & 52 & 58 & 77 & 49 & 48 & 88 \\
\hline $\mathrm{R}^{*}$ & 38 & LR & 12.07 & 17.07 & 99.84 & 22.75 & 75 & 78 & 101 & 75 & 78 & 101 \\
\hline $01^{* *}$ & 60 & LR & 13.20 & 13.20 & 89.91 & 28.45 & 96 & 107 & 75 & 78 & 93 & 71 \\
\hline $\mathrm{O} 2^{* *}$ & 41 & LR & 10.38 & 10.38 & 83.22 & 23.87 & 80 & 93 & 74 & 78 & 91 & 74 \\
\hline $\mathrm{O}^{* *}$ & 50 & $\mathrm{LR}^{\mathrm{im}}$ & 16.22 & 16.22 & 100.0 & 34.68 & 96 & 101 & 80 & 71 & 81 & 74 \\
\hline $\mathrm{O} 4^{* *}$ & 51 & LR & 12.30 & 12.30 & 94.77 & 24.70 & 91 & 97 & 79 & 75 & 81 & 78 \\
\hline O5* & 56 & L & 9.40 & 9.40 & 72.19 & 15.56 & 65 & 86 & 65 & 65 & 86 & 64 \\
\hline
\end{tabular}

R: Restrictive; O: Obstructive; LR: Loco-regional; L: Local; MLD: Mean lung dose; Vx: Percentage volume of lung receiving $\geq x$ dose. ${ }^{*}$ The patient was restrictive or

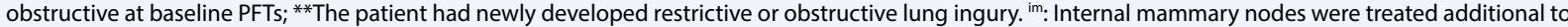
whole breast.

patients were treated using HT. They performed total dose 42 Gy in 15 fractions with simultaneous boost as a short course RT but not conventional RT in 50 Gy in HT arm and assessed pulmonary function via FEV1 and diffusing capacity of the lung for carbon monoxide (DLCO) prior to RT and 2 months after completion of RT. In their study, lung toxicity significantly reduced in HT arm according to measurements of DLCO but not FEV1 ( $\mathrm{p}=0.047)$. We treated 40 patients with breast cancer using HT and found statistically significant reduction in FEV1 and FVC at 3 months after RT $(\mathrm{p}<0.05)$. However, in assessment 3 months after RT, restrictive pattern newly developed in 3 patients and obstructive pattern developed in 4 patients based on measurements of PFTs. Except one patient developed restrictive pattern, other obstructive or restrictive patients underwent loco-regional RT. She received concurrent trastuzumab with 50 Gy whole breast and 10 Gy lumpectomy cavity boost RT. The value of ipsilateral lung V20 was $22.68 \%$ in this patient and she received concurrent trastuzumab. We found that decrease in FVC at 3 months after RT was significantly more in the patients were given concurrent trastuzumab with $\mathrm{RT}$ ( $\mathrm{p}=0.022$ ). The incidence of trastuzumab-induced pneumonitis has been reported in the literature as $0.4-0.6 \%$.[19] Of our patients $97.5 \%$ including this restrictive patient had been given taxancontaining regimen although this regimen was not found efficient on PFTs in our study. Paclitaxel cause pneumonitis usually develop 1 week to 3 months after treatment with estimated frequencies of $0.73-12 \%$ [20-22]. This suggests to us that new developing restrictive disease may be independent of the lung dose for this patient. One of patients developed obstructive pattern after RT had inner quadrant tumor and multiple high-risk recurrence factors. This patient had also large breast volume $\left(1621.50 \mathrm{~cm}^{3}\right)$ received adjuvant 50 Gy RT to whole breast and internal mammary nodes on the first three intercostal space and $16 \mathrm{~Gy}$ boost to lumpectomy cavity following breast conserving surgery. Therefore, the value of ipsilateral lung V20 was very high with $34.68 \%$. It has been found a correlation between the risk of RP and value of ipsilateral lung V20 in breast cancer irradiation. The incidence of RILD rises up to $7.5-11.5 \%$ if the value of ipsilateral lung receiving $20 \mathrm{~Gy}$ increase to $20-30 \%$.[18,23,24] Similarly, we found that in the group $(n=4)$ with the value of ipsilateral lung V20 $\geq 30 \%$, decrease in FVC at 3 months after RT was more ( $\mathrm{p}=0.019)$. In our study, in one patient (Table $5, \mathrm{R} 1^{\star *}$ ), value of ipsilateral lung V20 was very low with $10.41 \%$. She was Her2 (-) and smoker unlike other restrictive or obstructive patients but she developed newly mild restrictive pattern with minimal reduction in baseline FEV1/FVC. The smoking has been found related to lower incidence of RILD. [25] Ten patients were smoker in our study and only one of them developed restrictive pattern after RT. This finding supports positive effect of smoking on RP. 
There are some limitations of this study. First, this study was performed with a single measurement tool to assess the pulmonary function; additionally to PFTs, we may be use DLCO that reflect properties of alveolar-capillary membrane. Second, we present preliminary results of our study. Thus, we cannot comment on long-term effects. However, our study will continue to assess late effects of breast irradiation with helical tomotherapy. Third, the characteristics such as stage and surgery of patients including in this study were heterogeneous. Thus, irradiated volumes were heterogeneous. Finally, the number of patients recruited was too small to allow drawing generalizations.

HT plans provide excellent conformity and homogeneity even in target volumes including lymph nodes in breast cancer irradiations. In very few patients, minimal changes in PFTs can be seen in the acute phase after RT with HT and these changes result in mild restrictive and obstructive pattern. Nevertheless, when considered the risk to benefit ratio, HT can be a viable option for breast cancer patients with complex volumes.

\section{Disclosure Statement}

The authors declare no conflicts of interest.

\section{References}

1. Davis SD, Yankelevitz DF, Henschke CI. Radiation effects on the lung: clinical features, pathology, and imaging findings. AJR Am J Roentgenol 1992;159(6):115764. Crossret

2. Crapo RO. Pulmonary-function testing. N Engl J Med 1994;331(1):25-30. Crossre.

3. Marks LB, Yu X, Vujaskovic Z, Small W Jr, Folz R, Anscher MS. Radiation-induced lung injury. Semin Radiat Oncol 2003;13(3):333-45. Crossree

4. Cendales R, Schiappacasse L, Schnitman F, García G, Marsiglia H. Helical tomotherapy in patients with breast cancer and complex treatment volumes. Clin Transl Oncol 2011;13(4):268-74. Crossre.

5. Goddu SM, Chaudhari S, Mamalui-Hunter M, Pechenaya OL, Pratt D, Mutic S, et al. Helical tomotherapy planning for left-sided breast cancer patients with positive lymph nodes: comparison to conventional multiport breast technique. Int J Radiat Oncol Biol Phys 2009;73:1243-51. Crossre

6. Dogan N, Cuttino L, Lloyd R, Bump EA, Arthur DW. Optimized dose coverage of regional lymph nodes in breast cancer: the role of intensity-modulated radiotherapy. Int J Radiat Oncol Biol Phys 2007;68(4):1238-

\section{Crossre}

7. Van Parijs H, Miedema G, Vinh-Hung V, Verbanck S, Adriaenssens N, Kerkhove D, et al. Short course radiotherapy with simultaneous integrated boost for stage I-II breast cancer, early toxicities of a randomized clinical trial. Radiat Oncol 2012;7:80. Crossre

8. Jeba J, Isiah R, Subhashini J, Backianathan S, Thangakunam B, Christopher DJ. Radiation Pneumonitis After Conventional Radiotherapy For Breast Cancer: A Prospective Study. J Clin Diagn Res 2015;9(7):XC01XC05. Erossre

9. Krengli M, Sacco M, Loi G, Masini L, Ferrante D, Gambaro G, et al. Pulmonary changes after radiotherapy for conservative treatment of breast cancer: a prospective study. Int J Radiat Oncol Biol Phys 2008;70(5):1460-7.

10. Kubo A, Osaki K, Kawanaka T, Furutani S, Ikushima $\mathrm{H}$, Nishitani $\mathrm{H}$. Risk factors for radiation pneumonitis caused by whole breast irradiation following breastconserving surgery. J Med Invest 2009;56(3-4):99-110.

11. Schytte T, Bentzen SM, Brink C, Hansen O. Changes in pulmonary function after definitive radiotherapy for NSCLC. Radiother Oncol J Eur Soc Ther Radiol Oncol 2015;117:23-8. Crossret

12. Stone B, Mangona VS, Johnson MD, Ye H, Grills IS. Changes in Pulmonary Function Following ImageGuided Stereotactic Lung Radiotherapy: Neither Lower Baseline Nor Post-SBRT Pulmonary Function Are Associated with Worse Overall Survival. J Thorac Oncol 2015;10(12):1762-9. Crossree

13. Wang S, Liao Z, Wei X, Liu HH, Tucker SL, Hu CS, et al. Analysis of clinical and dosimetric factors associated with treatment-related pneumonitis (TRP) in patients with non-small-cell lung cancer (NSCLC) treated with concurrent chemotherapy and three-dimensional conformal radiotherapy (3D-CRT). Int $\mathrm{J}$ Radiat Oncol Biol Phys 2006;66(5):1399-407. Crossre

14. Chow TL, Louie AV, Palma DA, D'Souza DP, Perera F, Rodrigues GB, et al. Radiation-induced lung injury after concurrent neoadjuvant chemoradiotherapy for locally advanced breast cancer. Acta Oncol 2014;53(5):697-701. Crossre

15. Pellegrino R, Viegi G, Brusasco V, Crapo RO, Burgos F, Casaburi R, et al. Interpretative strategies for lung function tests. Eur Respir J 2005;26(5):948-68. Crossret

16. Gokula K, Earnest A, Wong LC. Meta-analysis of incidence of early lung toxicity in 3-dimensional conformal irradiation of breast carcinomas. Radiat Oncol 2013;8:268. Crossret

17. Toma CL, Ciprut T, Bugarin S, Roşca D, Bogdan MA. Radiation induced lung injuries secondary to radiotherapy for breast cancer. [Article in Romanian] Pneumologia 2011;60(1):40-6. [Abstract] 
18. Lind PA, Wennberg B, Gagliardi G, Fornander T. Pulmonary complications following different radiotherapy techniques for breast cancer, and the association to irradiated lung volume and dose. Breast Cancer Res Treat 2001;68(3):199-210. Crossre

19. Vahid B, Marik PE. Pulmonary complications of novel antineoplastic agents for solid tumors. Chest 2008;133(2):528-38. Crossret

20. Ramanathan RK, Reddy VV, Holbert JM, Belani CP. Pulmonary infiltrates following administration of paclitaxel. Chest 1996;110(1):289-92. Crossret

21. Suzaki N, Hiraki A, Takigawa N, Ueoka H, Tanimoto Y, Kozuki T, et al. Severe interstitial pneumonia induced by paclitaxel in a patient with adenocarcinoma of the lung. Acta Med Okayama 2006;60(5):295-8.

22. Weiss RB, Donehower RC, Wiernik PH, Ohnuma T,
Gralla RJ, Trump DL et al. Hypersensitivity reactions from taxol. J Clin Oncol Off J Am Soc Clin Oncol 1990;8:1263-8.

23. Chie EK, Shin KH, Kim DY, Kim T-H, Kang H-S, Lee ES, et al. Radiation Pneumonitis after Adjuvant Radiotherapy for Breast Cancer: A Volumetric Analysis Using CT Simulator. J Breast Cancer 2009;12:73. Crossre

24. Onal C, Oymak E, Kotek A, Efe E, Arslan G. Correlation of conventional and conformal plan parameters for predicting radiation pneumonitis in patients treated with breast cancer. Breast Cancer 2012;15:320-8.

25. Bjermer L, Franzén L, Littbrand B, Nilsson K, Angström T, Henriksson R. Effects of smoking and irradiated volume on inflammatory response in the lung of irradiated breast cancer patients evaluated with bronchoalveolar lavage. Cancer Res 1990;50(7):2027-30. 